\title{
Analysis of Sino-American Family Education Differences: Collectivistic or Individualistic?-Taking the Glass Castle as an Example
}

\author{
Liu Yang ${ }^{1} \&$ Yang Congzhou ${ }^{1}$ \\ ${ }^{1}$ English Department, North China Electric Power University, Baoding, China \\ Correspondence: Yang Congzhou, NO. 689 Huadian Road, English Department, North China Electric Power \\ University, 071003 Hebei, China. Tel: 151-0028-0179. E-mail: 530485832@qq.com
}

Received: February 23, 2018

Accepted: April 21, $2018 \quad$ Online Published: July 28, 2018

doi:10.5539/ies.v11n8p51

URL: https://doi.org/10.5539/ies.v11n8p51

\begin{abstract}
Family education is the earliest, longest and the most common way of education, which has a deep influence on the growth of human beings. Due to the differences in value between China and the United States, the concepts of family education in both countries are also different. Value is one of the important parts of culture, whose core content is individualism and collectivism. Based on the two kinds of value, this paper takes the novel Glass Castle as an example to compare Chinese family education with American family education and finally proposes ways to improve Chinese family education.
\end{abstract}

Keywords: family education differences, collectivism, individualism, China, America

\section{Introduction}

Education is a kind of social activity which can cultivate people. It is the basic way to inherit social culture and pass on production experience and life experience (Yuan, 2004). Education begins with the family. The world outlook, the outlook on life, and the values of the teenagers start from the family (Zhai, 2016). Family education refers to the educational influence of parents on children's growth in the process of family interaction (Kang, 2008). Family education is different from school education and social education in that children begin to receive family education from the first day of their birth. Their parents are their first teachers. Family education is the basis of life education which plays a very important role in the formation of children's good or bad habits and healthy or unhealthy development of their body and mind. At the same time, education is a cultural phenomenon which reflects social and cultural connotations. China and the United States are in different cultures, which results to different education and consequently different family education. What elements in culture influence education and family education most? It is the value. Value is an important part of culture, of which individualism and collectivism are one of its core contents. In the study of cultural differences between China and the United States, the research on values difference is very important of value system. Is universally believed that Chinese tend to collectivism, and Americans tend to individualism. This paper will study the differences of family education between China and the United States from the perspective of collectivism and individualism.

\section{Definition of Collectivism and Individualism}

\subsection{Definition of Collectivism}

Collectivism is a cultural concept which is closely related to the thought of human civilization and progress. It is a part of the socialist ideology (Du \& Zhao, 2011). Collectivism is characterized by a rigid social framework that distinguishes between in-groups and out-groups ( $\mathrm{Li}, 2011)$. The scientific meaning of collectivism is to obey the collective interests when the individual interests and collective interests are incompatible. Hofstede (2001) suggested that the characteristic of collectivist culture is that individuals are protected by forming close team relationships and individuals are loyal to collective interests. Luo (2012) offered an excellent interpretation of collectivism: collective interests have precedence over personal interests. Collective interests are higher than individual interests, and collective interests are preferred to individual interests. However, "collective" refers to a common "group" of a state, a nation or a society, etc. It can also be a particular group under different conditions. The collective embodies the will of the whole team rather than the will of the leader. It is worth mentioning that collectivism does not mean that personal interests are completely negated. Even though all actions and 
statements are committed to collectives, collectivism does not obliterate individual interests. An important aspect of collectivism is to promote and protect the realization of the legitimate interests of the individual. Collectivism emphasizes the realization of the harmonious relationship between individuals and collective under the principle of collective justice. Through such a harmonious relationship, common development of collective and personal interests can be achieved. Collectivism emphasizes the dialectical unity of collective and individual interests (Luo, 2012). The so-called "sacrificing personal interests for the benefits of the collective" is based on respect for wills of individuals. It is not the coercion imposed on individuals by collective (Ding, 2011). It is improper to regard the opinion of "collective interest precedence over individual interest" and "freedom", "justice", "human rights", "humanitarianism" as opposed to each other.

\subsection{Definition of Individualism}

The ideological origin of individualism can be traced back to the ancient Greek philosophy, the Renaissance of Europe and the reformation of religion (Wei, 2010). In 1840, Tocqueville, the French political thinker, created the word "individualism". He equated personal values, dignity, happiness, interests and freedom as individualism and endowed it with a complete theoretical connotation: the realization of individual is the final aim and the society is only the means to achieve individual aims; individualism emphasizes individual democracy and freedom; social system which maintains private property from the perspective of the individual is emphasized. Hofstede argued that individualism is the degree to which a person acts as an individual rather than as a member of a group. Individualists are likely to be more independent, self-contained and self-collected. Individualism emphasizes personal freedom and individual rights and maximizes personal creativity and initiative. Li and Song (2003) explained individualism in three aspects: at the economic level, it takes advantage of egoism as the fundamental motive of all economic behavior and takes whether it is beneficial to the individual's interests as a fundamental evaluation standard. At the political level, it highlights the basic rights of individuals and regards maintaining and safeguarding individual rights as the fundamental value of social politics and legal system. At the cultural level, it pays attention to individual choice, self-struggle and self-emancipation.

\section{Chinese Collectivism and American Individualism}

\subsection{Chinese Collectivism}

Collectivism is the primary value and one of the main cultural models in China (Ding, 2011). In China's five-thousand-year history, the characteristics of collectivism are permeated in culture. Chinese collectivist culture mainly developed from Confucianism. Confucius advocated "benevolence" and "courtesy". The "courtesy" refers to that people should behave orderly under the public environment. Living a collective life, people must strictly abide by their own collective identity, obey superiors' orders and do what they should do. Especially in wars, collectivism is highly emphasized in that people should sacrifice lives for a common goal for collective services. Thus, Chinese adore the hero who sacrifices himself to the contributions to the collective. In today's life, China has also been emphasizing collectivism. The hierarchical division of the importance of nation, society and individuals goes like a pyramid. It is believed that individual interests should be subordinated to social interests, social interests to national interests, and national interests are the top concern.

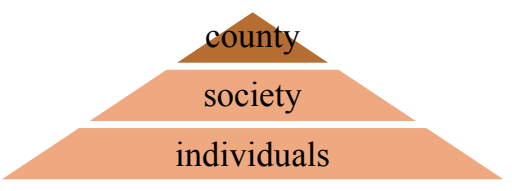

Figure 1. Arrangement of individual, social and national interests

\subsection{American Individualism}

Robert Bellah, a sociologist of the University of California, argued that "individualism is the true core of American culture." Individualism permeates all aspects of American life, including family life. Individualism comes from its traditional autarkic living style. Each family, either owing an acre of land or a workshop, is an independent production unit (Chen, 1996). This is the historical basis of American individualism. Influenced by multiculturalism and pluralistic concept, Americans are willing to accept new ideas and cultures without any restriction (Lizza, 2008). Individualism, till now, stays unchanged. All achievements, in its over-200-year history, cannot be separated from individualism. Firstly, individualism lays stress on equality. The individualistic spirit 
shows that everyone is equal whether he is the president of the country or just ordinary people. Under the guidance of equal thoughts, everyone has the right to gain his own happiness through indefatigable endeavors. Secondly, individualism thinks highly of action. R.W. Emerson, one of the greatest ideologists of America in the 19th century, once said, "If we must have great actions, let us make our own actions great first. All actions have an infinite flexibility. The smallest actions also allow the air to fill up, until they make the sun and moon dim" (Zhao, 1993). Active action is one of major features of individualism. What's more, in reality, Americans emphasize open and direct expression of their ideas indicating individual freedom and rights. That is, they have the rights to express their inner thoughts in front of anyone. Besides, individualists also protect their own interests at the same time. In the relationship between the individual and the collective, the individual is seen as the starting point, the core and the aim while the state and the society are seen as the human organizations which are made up to protect the individual's rights and interests (Xiong, 2009). Individualism in the United States teaches people to think independently and not to listen to others' unconditional opinions or commands. Americans are taught to fight for themselves and to achieve their goals. They think that success is in their hands. They never wait for the aid of others, nor wait for the opportunity to come, but to create opportunities to change their fates (Ding, 2010).

\section{Differences in Family Education between China and the United States}

\subsection{Different Relationship between Family Members}

The relationship of family members in China emphasizes hierarchy and cohesion. From the ancient times, China formed large family structures with all the relatives of the family living together. Take the preserved Beijing Courtyard Houses as an example. Family members live together, and the locations of their housing are arranged according to family status, that is, the relationship of family members is hierarchical. Elders have the categorical authority. At the same time, elders also maintain the obligation of taking care of their offspring in every aspect. In a collective, the more authority a man possesses, the more duty he will perform. This is because the leader of a collective is considered responsible for every person in this collective. With the same principle, Chinese parents would like to arrange everything for their children. They simultaneously hope that children can fulfill the obligations of being a child and support them when they are old. The idea prevails not only in the rural areas of China but also in cities. The statistics show that $30 \%$ of the aged in the city have financial support from their children, while above $60 \%$ in the rural areas (Liu, Sun \& Zhang, 2006). Another survey data shows that $85 \%$ of the elderly want their spouse or children to take care of their daily life (Gao, 2010). When their children have offspring, parents zealously help their children to take care of their grandchildren, who are considered as the continuation of their lives and their family. There is a compact relationship between parents and children. The hierarchical and cohesive relationship reflects a strong sense of collectivism. This kind of relationship in China relates to responsibility, obligation and unity. As a group, Chinese take their families as the core. They do their best to support their collective.

The relationship of family members in America emphasizes equality and independence because the American concept of family is based on the idea of freedom, independence and equality. It is believed that every member of the family, including a two-year-old child, is a free, independent and equal individual (Shen, 2010). Gary (2004) argued that Americans consider themselves as independent individuals from an early age, and they think they are responsible for their own living conditions and destiny. In the United States, the child will leave his family and make a living alone when he grows up, usually at 18. In the novel The Glass Castle, the heroine's parents lived a "hard" but independent life with their children. Even though the heroine's grandmother was rich enough to help them live a better life, they didn't accept it. When the heroine grew up, her parents were still very poor, but they didn't seek help from their children and still lived in their own way. It can be seen that the relationship between family members is not tightly tied. They do not depend on each other or be involved too much in each other's life. The heroine's father was estranged from her grandmother, but the heroine's mother said she had no choice because he was her husband. The mother did this to separate herself from her native family. After marriage, she had her own life and didn't want her parents to interfere. The concept of individualism guides Americans to be apart from the family and pursue their own life. Under the influence of individualism concept, being born by parents is seen as a historical or physiological event. When children are young, parents are responsible for children; But when the child reaches the "independence age", the intimate bond of child-parent is loosened and sometimes even broken ( Gary, Amanda, \& Suan, 2004).

\subsection{Different Educational Purposes}

The purpose of family education is the starting point and basis of carrying out family education activities and it is also the destination of educational practices. The educational tasks, educational contents, educational methods 
and means of family education, as well as various educational activities, are based on the purpose of certain family education (Cao, 1998). Chinese parents regard having a good life as the purpose of education. Under the influence of collectivist values, parents should be responsible for the children in all aspects including education, health, morality and others and they wholeheartedly "give" their children a good life by providing them with good educational conditions. They hope that their children can be well-educated, get a good occupation and live a good life so that their children's lifetime can be spent smoothly, all with their endless efforts. Under the influence of the view that education is a precondition for a good life, Chinese parents pay great attention to their children's education and try to make their children get high marks in extreme way of reducing entertainment time of their children or allowing children not to do housework. Chinese parents attach great importance to high marks and affirm that getting high marks means their children will have more chances to choose best universities and to get satisfying and decent jobs so that their children will have a qualified life and a comfortable living. Moreover, another purpose of Chinese family education is "being a good man of the society". The collectivism holds the view that the collective is the most important virtue so the parents want their children to get ratification of the collective. It is widely accepted that "a good man" must possess qualities requested by the collective.

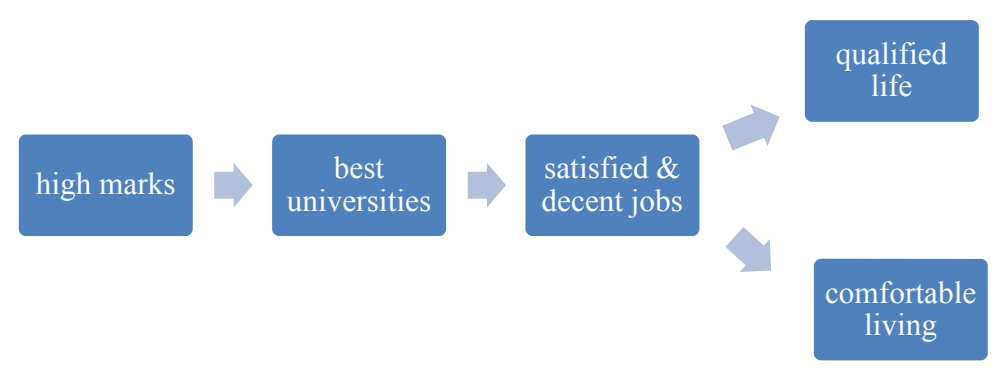

Figure2. Chain effects in the views of Chinese parents on children's education

The purpose of family education in the United States is to cultivate children to adapt themselves to various living conditions and get independent living abilities, that is, to make the children live their own life. Family education in the United States emphasizes the learning of knowledge and skills needed in reality. The development of individual potential is also underlined (Liu, 2016). American parents try to create opportunities and conditions for self-training for children so that children can get enough exercise in various environments (Sun, 2002). In the novel The Glass Castle, even though the children don't go to school, they don't stop learning because their father teaches them knowledge, all the thing including survival skills - something that can't be learned at school. For example, the father does not require children to grow up in accordance with the educational contract of society but demands his children to naturally acquire necessary survival skills, for example, how to protect themselves in the desert when the sandstorm comes. Another purpose of American education is to educate children into an independent person who is responsible for himself. The father's educational view also reflects the influence of individualism on the responsibility of parents which reflects the individualistic values of the Americans. Different from the responsible Chinese parents, American parents have limited liability for their children in that they will not undertake all things of their children (Zhang, 2005). Parents are responsible for themselves, not for their children. For instance, in the novel The Glass Castle, the heroine can cook for herself when she was only 3 years old. She knew that her mother had her own things to do and her mother was not born to cook for her. Less interference in children's lives will foster the realization of self-value and personal liability of children. This reflects the individualism concept which thinks highly of individual responsibility. Americans attach great importance to the education of responsibility of children. For example, the high school graduation ceremony is highly valued by parents. After the school graduation ceremony, each family also organizes a family party to celebrate the children's graduation and adulthood (Zhang, 2005). These ceremonies are used to tell the children that he/she is an adult who is responsible for himself/herself.

\subsection{Different Ways of Education}

Chinese family education tends to be a "force" education. That is, children should listen to their parents, say, which school to attend or what subjects to learn. Chinese parents often adopt imperative sentences like "Turn off the TV now.", "Go to bed." or "Do not play the mobile phone." to tell their children what to do or what not to do. This imperative mood not only lets the child know what he should do, but also shows the authority of the parents, that is, in Chinese family, elders have absolute authority which cannot be queried. When parents do 
something wrong, they often do not actively admit their mistakes. This is because parents have absolute authority, and as the superior they cannot be wrong, which sounds illogical because to Chinese parents admitting mistakes means losing face, but parents should not lose face especially in the face of their children. Being the authority, parents have absolute leadership and control over the child. The parents try to arrange all things in life for the children and fail to leave enough personal space and options for their children to choose. However, it is not always wrong when children's affairs are entirely decided by the parents. With rich experience in life, parents can give children a lot of useful suggestions and guidance. This is also affected by collectivism, which approves that all people should follow a set of ethical system, in which children should obey their parents and the parents have rights to make arrangements for their children. When viewed from a macro perspective, Chinese family education tends to go with the stream. Parents will ask their children to learn things which are considered as useful skills by "others". To Chinese parents, if one thing is wild accepted by the collective, it must be a perfect and useful thing. Nowadays, in China, many children are required to learn to play the piano or attend Mathematical Olympiad even though they are not adept at those skills. The collective has the indisputable correctness in that Chinese are convinced that if one thing is accepted by collective, it is undoubtedly right. In addition, Chinese family education also prefers horizontal comparison, that is, parents prefer to compare their children with other children to highlight their excellent education abilities either for the better performance of their children or for other children to follow. Children's high scores mean the success of a family education while poor scores mean the failure. Parents relate children's educational achievement to the degree of their own satisfaction and achievements. It also reflects the collectivism of the Chinese people in which people use the collective standard to measure their own level and focus on the gap between themselves and the collective.

American family education tends to be an "interest" education. American parents hold the view that it is more advantageous to carry out education according to the characteristics of each child (Zhang, 2008). American parents adopt the way that can guide and inspire their children. "Try" and "go" are the most frequently used words (Huang, 2009; Huang, 2009). Parents encourage children to explore the surrounding environment from childhood. The children can do whatever they want. The development of children's self-awareness is highly emphasized, and children learn to express themselves frankly. Individualism focuses on individuals in that American parents rarely compare their children with other children. They use "children's standards" to evaluate children so that children develop their own unique personalities. Parents pay attention to the development of children's individual freedom and harmony, so most of the children in the United States have distinctive personality. This reflects the individualism of America. In the novel The Glass Castle, the father tells his children how to protect themselves in the sandstorm and how to sleep in the desert without pillows and so on. He helps to develop children's abilities to survive, which are necessary for the children to live independently when they grow up. It has nothing to do with other people, and there is no need to compare. Paying attention to the development of children themselves also embodies an individualistic point of view in that parents do not put their children in the comparison with others. Besides, compared with Chinese parents, Americans encourage children more than protect them. Children are encouraged to have a spirit of adventure, to overcome shyness, and to compete with others (Li, 2005). For example, American parents encourage their children to take part in challenging sports such as skateboarding. Parents encourage children to try, to learn, to practice, to cultivate ability and interest, and, most importantly, to build up self-confidence. To encourage their children, American patents often use suggestive sentences like "I think... would be better.", "I suggest that..." "Would you like to listen to my opinion" (Zhang, 2005).

\section{The Enlightenment of American Family Education to Chinese Family Education}

\subsection{Building a Family Relationship of Equality and Democracy}

Equal relationship leads to mutual respect and understanding. We should advocate equal relationship between parents and children. In China, parents have absolute authority. Chinese parents require children to obey them so that children's right to express their opinions is limited. The president of the United States, Nixon, once said, "The task of China's education system is to bring the child into a gentle, fully compliant person, so they will lose Darwin and Einstein of China" (Lizza \& Huang, 2008). As Nixon said, unequal family relationship may weaken a child's unique personality and creativity. In addition, parents' control over their children means that they are responsible for their children. With this great sense of responsibility, on the one hand, parents lose their own private space for life, and on the other hand, children feel that everything is arranged for him and take it for granted, which results in their sluggishness of taking efforts. In the long run, not only do children lack independent ability and creativity, but also they are not grateful for what their parents have done for them. This then leads to the result that children don't know how to love their parents and the only thing they know is being loved. It is necessary to establish an equal relationship and let the children know more about their parents' effort 
to raise them so that they can feel the hardships and love of their parents. In the novel The Glass Castle, the heroine can cook for herself when she was only 3 years old. She knew that her mother had her own things to do and her mother was not born to cook for her. The relationship between her family members was equal. It is vital to form an equal and democratic relationship. This will arouse the affection of a child to his parents and also his responsibility to the family and will promote family harmony and enhance children's autonomy.

\subsection{Pay Attention to the Cultivation of Children's Comprehensive Ability}

Comprehensive ability is reflected in many aspects. Chinese family education often ignores skills such as life skills, job skills, communication skills, etc. (Lizza \& Huang, 2008). In a questionnaire launched in China called "How to train the creativity of teenagers", a question was asked "what would you do if you found out that your child was trying to open an alarm clock?" $40 \%$ of parents answered they would blame their children and $48 \%$ of parents answered they would deal with this affair impatiently. Chinese family education not only ignores some practical abilities, but also ignores comprehensive abilities, including learning ability and creativity (Lizza \& Huang, 2008). A favorable family education can cultivate children's learning ability, self-protection ability, and the ability for love, etc. It can also improve children's potential, moral cognition and cultivate children's good character. In contrast, the content of family education in the United States is abundant. Attention is paid to the harmonious development of children in physical, cognitive, linguistic, social and emotional aspects ( $\mathrm{Li}, 2007)$. The current Chinese family education sets "success" as their purpose, which means that intellectual education overrides everything. Such education will make children obtain a unilateral and misshapen development. Children will become a bookworm who cannot adapt to the changing social environment. Therefore, in family education, parents should help to improve children's comprehensive quality and the overall quality. It is necessary to change the one-sided education to all-round education. What's more, we cannot ignore the potential of moral cultivation of temperament. Nowadays, schools in China pay attention to quality education, but in family education, many parents still take study as the main task of their children, so it is important to cultivate children's comprehensive abilities in family education.

\subsection{Improve the Quality of Parents}

Parents are the first teachers of the children. Children can be taught by precept and example so parents' every word and action will have a huge impact on the development of children. Children's moral values and values are derived from diplomacy, especially from their diplomacy with parents. Therefore, parents have a great influence on their children's thought (Lizza \& Huang, 2008). After all, Education is dynamic. Under the background of changeable times, family serves as the cradle of education and the aircraft carrier of moral education. Chinese parents depend too much on the school education for their child while they easily ignore their own education. In fact, parents need to learn continually and improve themselves in the various aspects, such as learning new things constantly, being polite, being honest and so on. Some parents require their children to do some things but they fail to do them by themselves. Such hollow and feeble education is meaningless. A convincing education is an effective education.

\section{Conclusion}

This paper attempts to analyze the differences of family education between China and the United States from the perspective of collectivism and individualism. It concludes the influence of culture on education and the relationship between culture and family education. That is, traditional cultural differences breed different family education, and different family education reflects different social and cultural connotations. We should learn experience from the advanced ideas of American family education and abandon some antiquated concepts on Chinese family education. Building a family relationship of equality and democracy, paying attention to the cultivation of children's comprehensive abilities and improving the quality of parents should be highly valued. Only in this way can we cultivate more talents who can make contributions to our country and society.

\section{References}

Cao, C. D. (1998). Discussion on the purpose of family education. Education Science, 1, 37-38.

Chen, B. (1996). Exploring the basic values of America from the aspect of family changes. Journal of Xiamen University (philosophy and social sciences edition), 2, 14-19.

Ding, X. Y. (2010). A comparison of Chinese and American values in intercultural communication-A brief discussion on collectivism and individualism. Journal of Tonghua Normal University, 7, 76-78.

Du, H. L., \& Zhao Z. D. (2011) A Summary of the Study of Collectivism at Home and Abroad. Morality and Civilization, 3, 147-151. 
Gao, W. (2010). An Analysis of the Diversified Rural Old-age Security System. Journal of Harbin Municipal Party School, 68, 43-45.

Gary A., Amanda, R. D., \& Suan, J. X. (2004). American. Beijing: China Water \& Power Press.

Hofstede, G. (2001). Culture's consequences: Comparing values, behaviors institutions, and organizations acrossnations (2nd ed.). Thousand Oaks, CA: Sage Publications.

Huang, X. Y., \& Huang, C. F. (2009). The Comparison and Enlightenment of Family Education between China and America. Journal of Wuhan University of Technology (social sciences edition), 4, 101-104.

Kang, Y. R. (2008). Cross-cultural Comparison and Enlightenment of Family Education Between China and America. Times Literary, 5, 187.

Li, L., \& Song, X. L. (2003). Western Individualism Values and American Spirit. Journal of Yantai University (Edition of social science), 4, 460-464. https://doi.org/10.13951/j.cnki.issn1002-3194.2003.04.020

Li, Y. (2005). The enlightenment of American family education. China Population Daily, 3.

Li, Z. Y. (2001). A comparison between American individualism and Chinese collectivism from the view of cherishing life in war. Overseas English, 13, 253-254, 286.

Li, Z. Y. (2007). Comparative analysis and countermeasures of family education between China and America. Forumon Contemporary Education, 6,138-139.

Liu, G. H., Sun, K. L., \& Zhang, J. L. (2006). The characteristics and influence of the change of family relations in China. Dongyue Tribune, 2,189-191.

Liu, W. R. (2016). American family education and its enlightenment to Chinese family education. China Woman, B04.

Lizza, P., \& Huang, L. (2008). Comparison of family education between China and the United States. Forum on Chinese Culture, S1, 233-237.

Luo, G. J. (2012). Problems on the principle of collectivism. Leading Journal of Ideological and Theoretical Education, 6, 36-39.

Shen, C. T. (2010). Unscramble of the differences between Chinese and American views on family. Cultural and history vision (Theoretical edition), 5, 39-40.

Sun, Q. R. (2002). The comparison and enlightenment of family education between China and the United States. Educator, 14, 2-5.

Walls, J. (2006). The Glass Castle. New York: Scribner.

Wei, X. H. (2010). A study on the duality of American individualistic values. Journal of Chongqing University of arts and sciences, 5, 92-95.

Xiong, X. J. (2009). Comments on American Individualism. Times Literary, 4, 206-208.

Yuan, Z. G. (2004). Contemporary Pedagogy. Beijing: Educational Science Publishing House.

Zhai, B. (2016). Establishing the values of family education in the new epoch. Educational Research, 3, 92-98.

Zhang, J. J. (2008). Study of the Essence of the Rise of Family Education in the United States. Popular Literature and Art (theoretical edition), 9,143-144.

Zhang, Y. C. (2005). Enlightenment of American family education. Heilongjiang Daily.

Zhao Y. F. (1993). Emerson Essays and Lectures. Shanghai: Shanghai Sanlian Bookstore.

\section{Copyrights}

Copyright for this article is retained by the author(s), with first publication rights granted to the journal.

This is an open-access article distributed under the terms and conditions of the Creative Commons Attribution license (http://creativecommons.org/licenses/by/4.0/). 